PROF. MARK HAMER (Orcid ID : 0000-0002-8726-7992)

DR. G. DAVID BATTY (Orcid ID : 0000-0003-1822-5753)

Article type : Rapid Communication

\title{
Association of objectively measured physical activity with brain structure: UK Biobank study
}

Mark Hamer, PhD, ${ }^{1,2}$ Nikhil Sharma, $\mathrm{PhD},{ }^{3} \mathrm{G}$ David Batty, $\mathrm{PhD}^{2}$

${ }^{1}$ School Sport, Exercise \& Health Sciences, Loughborough University, UK.

${ }^{2}$ Department of Epidemiology and Public Health, University College London, London, UK.

${ }^{3}$ MRC Unit for Lifelong Health and Ageing, University College London, London, UK

Correspondence: Professor Mark Hamer, National Centre for Sport and Exercise Medicine - East Midlands, Loughborough University, Loughborough LE11 3TU, United Kingdom. Email:

m.hamer@lboro.ac.uk

Short title: Physical activity and brain health

This article has been accepted for publication and undergone full peer review but has not been through the copyediting, typesetting, pagination and proofreading process, which may lead to differences between this version and the Version of Record. Please cite this article as doi: 10.1111/joim. 12772

This article is protected by copyright. All rights reserved. 


\section{Abstract}

Background: Physical activity may be beneficial for cognition but mechanisms are unclear. We examined the association between objectively assessed physical activity and brain volume, with a focus on the hippocampus region.

Methods: We used data from UK Biobank ( $n=5,272$; aged $55.4 \pm 7.5$ yrs; $45.6 \%$ men) collected through 2013-2016. Participants wore the Axivity AX3 wrist-worn triaxial accelerometer for seven days to assess habitual physical activity. Structural magnetic resonance imaging was performed using a standard Siemens Skyra 3T running VD13A SP4 to obtain images of the brain.

Results: There was an association between physical activity (per SD increase) and grey matter volume after adjustment for a range of covariates, although this association was only detected in older adults ( $>60$ yrs old). We also observed associations of physical activity with both left $(B=0.52,95 \% \mathrm{Cl}, 0.01,1.03 ; \mathrm{p}=0.046)$ and right hippocampal volume $(B=0.59,95 \%$ $\mathrm{Cl}, 0.08,1.10 ; \mathrm{p}=0.024)$ in covariate adjusted models.

Conclusion: In summary, physical activity may play a role in the prevention of neurodegenerative diseases.

Keywords: Physical activity; neurodegeneration; hippocampus; population

This article is protected by copyright. All rights reserved. 


\section{Introduction}

With treatments for dementia and cognitive impairment elusive, there is a parallel interest in prevention via modifiable risk factors. Position statements and systematic reviews of the literature have suggested a role for selected nutritional factors, cigarette smoking, certain somatic medical conditions and cognitive training, although the evidence base, while voluminous, is inconclusive. Given its cardioprotective properties, and an apparent vascular origin for cognitive decline and dementia, there is also interest in the potential role of physical activity [1-4]. Meta-analyses of cohort studies have demonstrated favourable associations between physical activity and cognitive outcomes [2,3]. The mechanisms underlying these relationships are, however, uncertain.

Hippocampal atrophy may be particularly relevant in relation to Alzheimer's disease [5], and several studies have demonstrated positive associations between physical activity, fitness and brain volume (grey and white matter) [6-13]. The existing studies are, however, small in scale (sample size range: 90 to 691 people). While offering imprecise results, small scale studies also fail to facilitate an examination according to important sub-groups such gender and age. It is also the case that in mechanistically-orientated studies of activity and cognition or dementia most [8-11], but not all $[12,13]$, have relied on assessments of selfreported physical activity which are subject to measurement error.

Accordingly, the aim of this study was to examine associations between objective physical activity and brain structure using data from a large scale population imaging study of over 5,000 adults. We hypothesized an association between physical activity and greater brain volume, particularly in the hippocampus region. We hypothesized stronger associations in older adults where atrophy is more advanced.

This article is protected by copyright. All rights reserved. 


\section{Methods}

\section{Participants}

We used data from UK Biobank consisting of participants aged 40-69 years when recruited in 2006-2010 [14]. Ethical approval was provided by the NHS National Research Ethics Service (Ref 11/NW/0382).

Physical activity assessment

Participants who had provided a valid email address were sent an invitation to wear an accelerometer for seven days. The participant email addresses were chosen randomly. From June 2013, participants were sent devices (the Axivity AX3 wrist-worn triaxial accelerometer) in order of acceptance. Details on the accelerometer protocol including data extraction and processing have been described elsewhere [15]. In brief, the accelerometers were programmed to start at $10 \mathrm{am}$ two working days after postal dispatch, and capture triaxial acceleration data over a seven day period at $100 \mathrm{~Hz}$ with a dynamic range of $+-8 \mathrm{~g}$. Participants were instructed to wear the device continuously and carry on with their normal activities. Physical activity was denoted as mean acceleration vector magnitude, representing overall activity as a continuous variable.

Structural Magnetic Resonance Imaging

In 2014, UK Biobank began inviting back 100,000 of the original volunteers for brain, heart and body imaging. Imaging data for 10,000 volunteers scanned between 2014-16 has

This article is protected by copyright. All rights reserved. 
already been processed, which is utilised in the present analyses. Total grey and white volume were estimated using structural magnetic resonance (MR) imaging. The MR imaging protocols have been described in detail elsewhere [16]. In brief, the study used a standard Siemens Skyra 3T running VD13A SP4 with a standard Siemens 32-channel RF receive head coil. For each scan, the field-of-view was automatically determined based on Siemens' autoalign software, which aligns a scout scan to an atlas. In the infrequent situation where autoalign failed, alignment was set by the radiographer. Structural images were acquired using straight sagittal orientation (i.e., with the field-of-view aligned to the scanner axes), with resolution of $1 \times 1 \times 1 \mathrm{~mm}$, field-of-view, $208 \times 256 \times 256$ matrix, over a duration of 5 minutes, with $1 \mathrm{~mm}$ isotropic resolution using a 3D MPRAGE acquisition. Full details on structural image segmentation and data normalization are provided elsewhere [17]. Data were processed using publicly available image processing tools, primarily taken from FSL (the FMRIB Software Library). Here we used the output of the standard biobank processing pipeline. All data were normalised for head size.

\section{Covariates}

During the clinic visit data were collected on age, sex, smoking history, frequency of alcohol intake (daily or almost daily, 1-2 times a week or monthly, never or almost never), education (college/degree; A-level; O-level; CSEs or equivalent; NVQ/HND or equivalent; other professional qualification; none), sleep duration ( $\leq 6 ; 7 ; 8 ; \geq 9 \mathrm{hr}$ per night), self-rated health (excellent; very good; good; fair; poor), and physician diagnosed cardiovascular diseases (including hypertension), major depression. Body weight was measured using electronic scales without shoes and in light clothing, and height was measured using a Stadiometer.

This article is protected by copyright. All rights reserved. 
Body mass index (BMI) was calculated using the standard formula [weight (kilograms)/height (meters) squared].

Statistical analysis

We modelled the associations between physical activity (per SD increase) and brain structure (total grey and white volume) using multiple linear regression. We also specifically examined associations between physical activity and hippocampal volume. Beta coefficients were initially adjusted for age, sex, and accelerometer wear time (Model 1), then for confounders such as smoking, alcohol consumption, body mass index, sleep, education, and health indicators (Model 2). We examined effect modification by fitting interaction terms for age (three categories) and sex. Analyses were performed using SPSS Version 22, with statistical significance $(p)<0.05$.

\section{Results}

The analytical sample comprised 5,272 adults (aged $55.4 \pm 7.5$ yrs; $45.6 \%$ men). Compliance was high: on average, participants wore the accelerometer device for $6.4 \pm 1.4$ days. More active participants (highest tertile) were younger, less likely to smoke, more likely to be degree educated, reported better self-rated health and lower prevalence of cardiovascular diseases, and lower BMI (Table 1).

This article is protected by copyright. All rights reserved. 
As illustrated in Table 2, covariates associated with grey matter volume included age, sex, smoking, alcohol and BMI. There was an association between physical activity and grey matter which was apparent after adjustment for age and sex, and persisted after covariates were added into the model (Table 2). Age significantly modified the association between physical activity and grey matter (Table S1); associations were evident in the older adults aged $60-69[n=2,108](p=0.028)$, but not in younger age groups (50 - 59 year olds, $[n=1,656] p=0.12 ; 40-49$ year olds, $[n=1,508] p=0.29)$. There were no gender differences in the activity-grey matter relation.

We observed associations of physical activity with both left $(B=0.52,95 \% \mathrm{Cl}, 0.01,1.03$; $p=0.046)$ and right hippocampal volume $(B=0.59,95 \% \mathrm{Cl}, 0.08,1.10 ; p=0.024)$ in covariate adjusted models. We did not observe any associations between physical activity and total white matter $(p=0.30)$.

Sensitivity analyses

We restricted all analyses to participants providing at least 3 days of accelerometry data $(n=$ 5,027 ), as a minimum of 72 hours of wear was shown to be closely reflective (within $10 \%$ ) of a complete seven day measure [15]. Results, however, remained unchanged. In a subsample of participants $(n=1,828)$ data on 'fluid intelligence' (a task with thirteen logic/reasoning-type questions and a two-minute time limit), and prospective memory [18] were available. Since cognitive status may influence brain structure and the ability to participate in physical activity we adjusted the models for fluid intelligence and memory

This article is protected by copyright. All rights reserved. 
although the association between physical activity and grey matter volume was largely unchanged (standardised $\beta=0.04, p=0.06$ ).

We conducted exploratory analysis to examine associations between physical activity and volumes of other specific brain regions using partial correlations adjusted for age and sex (Table S2). Physical activity was associated with various regional brain volumes, and associations with the pallidum $(\beta=0.030, p=0.03)$ and accumbens regions $(\beta=0.037, p=0.006)$ were robust to further covariate adjustments (including smoking, alcohol, BMI, self-rated health, CVD, depression, sleep, education).

\section{Discussion}

The aim of the present analyses was to examine associations between objective physical activity and brain structure using data from a large, population-based imaging study. A key finding was an apparent link between physical activity and higher grey matter volume that was only evident in older (>60yr old) participants. We also observed associations of physical activity with both left and right hippocampal volumes, which may have particular relevance to neurodegenerative diseases such as Alzheimer's.

In previous small scale longitudinal studies, self-reported physical activity at baseline was associated with larger grey matter volume [9-11], larger white matter volume [10] and higher total brain volume $[10,11]$ at follow up. In a study of 352 older adults (mean age 79.1 yrs) objectively assessed activity was associated with 5 year changes in grey and white matter volumes [12]. The present study builds on existing data by examining these

This article is protected by copyright. All rights reserved. 
associations using objective physical activity measures in a much larger population sample. Our findings are consistent with existing evidence suggesting stronger associations between physical activity and grey matter than with white matter. Our findings relating to hippocampal volume are partly consistent with evidence from exercise trials showing positive effects on left hippocampal volume but not total volume [19].

The main strength of our study was the vastly superior sample size compared with other studies, giving us sufficiently greater statistical power to explore, for example, effect modification by age and sex. There are also limitations. Since this study was cross-sectional we cannot discount the possibility that greater grey matter beneficially drives physical activity behaviour as opposed to the hypothesized direction. Indeed, recent data has suggested cognitive decline may lead to reduced activity [20], although when we adjusted for fluid intelligence the association between physical activity and grey matter volume was largely unchanged. Physical activity and imaging data were not collected concurrently and there may be variation in the time lag between the two measures. Numerous biomedical data have been shown to correlate with brain derived variables in the UK Biobank study [16], although our analyses took a theory driven approach where covariates were selected on an a priori basis.

This article is protected by copyright. All rights reserved. 


\section{Acknowledgements}

This research has been conducted using the UK Biobank Resource under Application Number 23476. Hamer acknowledges support from the NIHR Leicester BRC.

\section{Conflict of interest}

None declared.

\section{References}

1. Plassman BL, Williams JW Jr, Burke JR, Holsinger T, Benjamin S. Systematic review: factors associated with risk for and possible prevention of cognitive decline in later life. Ann Intern Med. 2010;153(3):182-193.

2. Blondell SJ, Hammersley-Mather R, Veerman JL. Does physical activity prevent cognitive decline and dementia?: A systematic review and meta-analysis of longitudinal studies. BMC Public Health. 2014 May 27;14:510.

3. Sofi F, Valecchi D, Bacci D, Abbate R, Gensini GF, Casini A, Macchi C. Physical activity and risk of cognitive decline: a meta-analysis of prospective studies. J Intern Med. 2011;269(1):107117

4. Hamer M, Chida Y. Physical activity and risk of neurodegenerative disease: a systematic review of prospective evidence. Psychol Med. 2009;39(1):3-11.

5. Karas $\mathrm{G}$, et al. A comprehensive study of gray matter loss in patients with Alzheimer's disease using optimized voxel-based morphometry. Neurolmage. 2003;18:895-907.

6. Gordon BA, Rykhlevskaia El, Brumback CR, Lee Y, Elavsky S, Konopack JF, et al. Neuroanatomical correlates of aging, cardiopulmonary fitness level, and education. Psychophysiology. 2008;45:825-838.

This article is protected by copyright. All rights reserved. 
7. Colcombe SJ, Erickson KI, Raz N, Webb AG, Cohen NJ, McAuley E, et al. Aerobic fitness reduces brain tissue loss in aging humans. J Gerontol A: Biol Sci Med Sci. 2003;58:176-180.

8. Benedict C, Brooks SJ, Kullberg J, Nordenskjold R, Burgos J, Le Greves M, et al. Association between physical activity and brain health in older adults. Neurobiol Aging. 2013;34:83-90.

9. Erickson KI, Raji CA, Lopez OL, Becker JT, Rosano C, Newman AB, et al. Physical activity predicts gray matter volume in late adulthood: the cardiovascular health study. Neurology. 2010;75:1415-1422.

10. Gow AJ, Bastin ME, Munoz M, aniega S, Valdes H, ernandez MC, Morris Z, Murray C, et al. Neuroprotective lifestyles and the aging brain: activity, atrophy, and white matter integrity. Neurology. 2012;79:1802-1808.

11. Rovio S, Spulber G, Nieminen L, Niskanen E, Winblad B, Tuomilehto J, et al. The effect of midlife physical activity on structural brain changes in the elderly. Neurobiol Aging. 2010;31:1927-1936.

12. Arnardottir NY, Koster A, Domelen DR, Brychta RJ, Caserotti P, Eiriksdottir G, Sverrisdottir JE, Sigurdsson S, Johannsson E, Chen KY, Gudnason V, Harris TB, Launer LJ, Sveinsson T. Association of change in brain structure to objectively measured physical activity and sedentary behavior in older adults: Age, Gene/Environment Susceptibility-Reykjavik Study. Behav Brain Res. 2016 Jan 1;296:118-24.

13. Tian Q, Glynn NW, Erickson KI, Aizenstein HJ, Simonsick EM, Yaffe K, Harris TB, Kritchevsky SB, Boudreau RM, Newman AB, Lopez OL, Saxton J, Rosano C; Health ABC Study. Objective measures of physical activity, white matter integrity and cognitive status in adults over age 80. Behav Brain Res. 2015 May 1;284:51-7.

This article is protected by copyright. All rights reserved. 
14. Sudlow C, Gallacher J, Allen N, Beral V, Burton P, Danesh J, et al. UK Biobank: An Open Access Resource for Identifying the Causes of a Wide Range of Complex Diseases of Middle and Old Age. PLoS Med. Public Library of Science; 2015;12: e1001779.

15. Doherty A, Jackson D, Hammerla N, Plötz T, Olivier P, Granat MH, White T, van Hees VT, Trenell MI, Owen CG, Preece SJ, Gillions R, Sheard S, Peakman T, Brage S, Wareham NJ. Large Scale Population Assessment of Physical Activity Using Wrist Worn Accelerometers: The UK Biobank Study. PLoS One. 2017 Feb 1;12(2):e0169649.

16. Miller KL, Alfaro-Almagro F, Bangerter NK, Thomas DL, Yacoub E, Xu J, Bartsch AJ, Jbabdi S, Sotiropoulos SN, Andersson JL, Griffanti L, Douaud G, Okell TW, Weale P, Dragonu I, Garratt S, Hudson S, Collins R, Jenkinson M, Matthews PM, Smith SM. Multimodal population brain imaging in the UK Biobank prospective epidemiological study. Nat Neurosci. 2016 Nov;19(11):1523-1536.

17. Alfaro-Almagro F, Jenkinson M, Bangerter NK, Andersson JLR, Griffanti L, Douaud G, Sotiropoulos SN, Jbabdi S, Hernandez-Fernandez M, Vallee E, Vidaurre D, Webster M, McCarthy P, Rorden C, Daducci A, Alexander DC, Zhang H, Dragonu I, Matthews PM, Miller KL, Smith SM. Image processing and Quality Control for the first 10,000 brain imaging datasets from UK Biobank. Neuroimage. 2018 Feb 1;166:400-424.

18. Lyall DM, Cullen B, Allerhand M, Smith DJ, Mackay D, Evans J, Anderson J, Fawns-Ritchie C, McIntosh AM, Deary IJ, Pell JP. Cognitive Test Scores in UK Biobank: Data Reduction in 480,416 Participants and Longitudinal Stability in 20,346 Participants. PLoS One. 2016;11(4):e0154222.

19. Firth J, Stubbs B, Vancampfort D, Schuch F, Lagopoulos J, Rosenbaum S, Ward PB. Effect of aerobic exercise on hippocampal volume in humans: A systematic review and meta-analysis. Neuroimage. 2017 Nov 4;166:230-238.

This article is protected by copyright. All rights reserved. 
20. Sabia S, Dugravot A, Dartigues JF, Abell J, Elbaz A, Kivimäki M, Singh-Manoux A. Physical activity, cognitive decline, and risk of dementia: 28 year follow-up of Whitehall II cohort study. BMJ. 2017 Jun 22;357:j2709.

Table 1. Characteristics of sample according to level of physical activity $(n=5,272)$

\begin{tabular}{|c|c|c|c|}
\hline \multirow[t]{2}{*}{ Variable } & \multicolumn{3}{|c|}{ Physical activity tertile based on mean acceleration data $(\mathrm{mg})$} \\
\hline & $\begin{array}{l}\text { Lower } \\
(\leq 24)\end{array}$ & $\begin{array}{l}\text { Middle } \\
(25-30)\end{array}$ & $\begin{array}{l}\text { Upper } \\
(\geq 31)\end{array}$ \\
\hline $\begin{array}{l}\text { Age at examination, yrs } \\
\text { (mean, SD) }\end{array}$ & $57.1 \pm 7.4$ & $55.7 \pm 7.4$ & $53.4 \pm 7.3$ \\
\hline $\begin{array}{l}\text { Sex }(\%) \\
\text { Women } \\
\text { Men }\end{array}$ & $\begin{array}{l}47.6 \\
52.4\end{array}$ & $\begin{array}{l}57.0 \\
43.0\end{array}$ & $\begin{array}{l}58.5 \\
41.5\end{array}$ \\
\hline $\begin{array}{l}\text { Education } \\
\text { (\% degree/college) }\end{array}$ & 40.9 & 43.3 & 46.4 \\
\hline Smoking (\%current) & 7.1 & 5.7 & 4.9 \\
\hline Alcohol (\%Daily) & 24.0 & 22.4 & 20.0 \\
\hline $\begin{array}{l}\text { Self-rated health (\% } \\
\text { excellent) }\end{array}$ & 18.5 & 24.8 & 27.7 \\
\hline $\begin{array}{l}\text { Sleep (hrs per night) } \\
6 \text { or less } \\
7 \\
8 \\
9 \text { or more }\end{array}$ & \begin{tabular}{|l}
21.4 \\
40.7 \\
29.7 \\
8.3 \\
\end{tabular} & \begin{tabular}{|l|}
20.9 \\
42.4 \\
31.2 \\
5.5 \\
\end{tabular} & \begin{tabular}{|l|}
22.0 \\
45.3 \\
28.3 \\
4.4 \\
\end{tabular} \\
\hline $\begin{array}{l}\text { Doctor diagnosed } \\
\text { cardiovascular disease }\end{array}$ & 29.4 & 22.4 & 16.5 \\
\hline Major depression & 2.6 & 2.8 & 2.6 \\
\hline Body mass index & $28.0 \pm 4.8$ & $26.5 \pm 4.0$ & $25.3 \pm 3.7$ \\
\hline
\end{tabular}

This article is protected by copyright. All rights reserved. 


\begin{tabular}{|l|l|l|l|}
\hline Whole brain Grey matter & $784419 \pm 49095$ & $795720 \pm 47075$ & $805730 \pm 46614$ \\
\hline Whole brain White matter & $708171 \pm 41434$ & $709695 \pm 47075$ & $714103 \pm 42079$ \\
\hline
\end{tabular}

Table 2. Association between physical activity and grey matter volume $(n=5,272)$

\begin{tabular}{|c|c|c|}
\hline & $\begin{array}{l}\text { Model } 1 \\
\text { Standardized coefficient } \beta \text { ( } p \text { - } \\
\text { value) }\end{array}$ & $\begin{array}{l}\text { Model } 2 \\
\text { Standardized coefficient } \beta \text { (p- } \\
\text { value) }\end{array}$ \\
\hline $\begin{array}{l}\text { Objective Physical activity } \\
\text { (per SD of acceleration) }\end{array}$ & $0.05(<0.001)$ & $0.03(0.01)$ \\
\hline Age (per unit) & $-0.55(<0.001)$ & $-0.54(<0.001)$ \\
\hline Sex (women=1; men=2) & $-0.30(<0.001)$ & $-0.28(<0.001)$ \\
\hline $\begin{array}{l}\text { Smoking (never=1; ex- } \\
\text { smoker=2; smoker=3) }\end{array}$ & & $-0.05(0.001)$ \\
\hline $\begin{array}{l}\text { Alcohol (ranging from, daily = } \\
1 \text { through to never }=5 \text { ) }\end{array}$ & & $0.05(0.001)$ \\
\hline $\begin{array}{l}\text { Self rated health (ranging } \\
\text { from excellent=1 through to } \\
\text { poor }=4 \text { ) }\end{array}$ & & $-0.01(0.46)$ \\
\hline $\begin{array}{l}\text { Doctor diagnosed CVD } \\
\text { (none=1; heart disease=2; } \\
\text { hypertension }=3 \text { ) }\end{array}$ & & $-0.01(0.33)$ \\
\hline Body mass index & & $-0.09(<0.001)$ \\
\hline $\begin{array}{l}\text { Major depression (none=1; } \\
\text { yes }=2 \text { ) }\end{array}$ & & $0.007(0.48)$ \\
\hline Sleep & & $0.02(0.08)$ \\
\hline $\begin{array}{l}\text { Education (ranging from } \\
\text { degree=1 through to none }\end{array}$ & & $0.006(0.59)$ \\
\hline
\end{tabular}

This article is protected by copyright. All rights reserved. 
=7)

Model 1; adjusted for age, sex, and accelerometer wear time.

Model 2; mutually adjusted for all variables presented.

This article is protected by copyright. All rights reserved. 